\title{
B-cell Deficiency: A De Novo IKZF1 Patient and Review of the Literature
}

Chen QY, Wang XC, Wang WJ, Zhou QH, Liu DR, Wang Y The Children's Hospital of Fudan University, Shanghai, People's Republic of China

J Investig Allergol Clin Immunol 2018; Vol. 28(1): 53-56 doi: 10.18176/jiaci.0207

Key words: IKAROS. Primary immunodeficiency. B-cell deficiency. IKZF1.

Palabras clave: IKAROS. Inmunodeficiencia primaria. Deficiencia de células B. IKZF1.

The IKZFI gene encodes a member of the family of hematopoietic zinc finger transcription factors, namely, IKAROS, which is involved in gene expression via chromatin remodeling. IKAROS plays a critical role in controlling hematopoiesis, particularly lymphoid cell differentiation, proliferation, and function. It is broadly expressed in hematopoietic cells [1].

We report the case of a 24-year-old woman who was the daughter of unrelated healthy parents of Chinese origin. She was previously a healthy child. At age 14 years, she had acute perforated appendicitis and a right ovarian cyst. Postoperative histopathology revealed gangrenous appendicitis and a benign cystic lesion of the right ovary. She had 2 episodes of pneumonia at 19 and 22 years, and both episodes required hospitalization. At age 22 years, the patient also had her spleen removed and underwent distal pancreatectomy because of a solid pseudopapillary tumor. She experienced occasional skin infections. In August 2016, she was hospitalized with a 2-month history of fever and was diagnosed with Enterococcus gallinarum sepsis. E gallinarum was repeatedly cultured from blood and cerebrospinal fluid. Laboratory tests disclosed the following results: white blood cells, $7.19 \times 10^{9} / \mathrm{L}$ (neutrophils, $55.9 \%$; eosinophils, $0.1 \%$; basophils, $0.3 \%$; monocytes, 7.4\%; and lymphocytes, 36.3\%); hemoglobin, $109 \mathrm{~g} / \mathrm{L}$; and platelets, $533 \times 10^{9} / \mathrm{mL}$. Liver function remained normal. T-spot, CMV/EBV antibody, and DNA were negative. Testing for ANA was positive. Immunologic examination revealed decreased serum IgG levels (2.07 g/L [normal range, 7-16]), low serum $\operatorname{IgA}(0.36 \mathrm{~g} / \mathrm{L}$ [0.7-4]), and low serum IgM levels $(<0.17 \mathrm{~g} / \mathrm{L}$ [0.4-2.3]). Lymphocytes subsets were as follows: CD3, 91.71\% (55\%-84\%); CD4, 24.55\% (31\%-60\%); CD8, 65.44\%(13\%-41\%); CD4/CD8, 0.38; CD19, 0.24\% (6\%$25 \%)$; NK, $7.17 \%(5 \%-27 \%)$. The results of testing for complement and dihydrorhodamine were normal. The patient was discharged after appropriate therapy with linezolid/ daptomycin/ampicillin and immunoglobulin replacement therapy. Based on her abnormal immunologic results, we performed whole exome sequencing (WES). The molecular analysis revealed heterozygous c.500A $>\mathrm{G}$, an $\mathrm{H} 167 \mathrm{R}$ mutation in exon 5 of the $I K Z F 1$ gene. Her parents' genes had no mutation at this locus, thus indicating a de novo mutation. 
Table. Mutations in IKZF1

\begin{tabular}{|c|c|c|c|c|c|c|}
\hline Family & Location & Domain & Onset Age & Nucleotide Substitutions & Amino Acid Substitution & Ref \\
\hline A & exon5 & ZF2 & $19 \mathrm{y}$ & c. $500 \mathrm{~A}>\mathrm{G}$ & P.H167R & - \\
\hline $\mathrm{B}$ & exon5 & $\mathrm{ZF} 2$ & $9 \mathrm{mo}$ & c. $476 \mathrm{~A}>\mathrm{G}$ & P.N159S & 2 \\
\hline $\mathrm{C}$ & exon5 & $\mathrm{ZF} 2$ & $9 \mathrm{y}$ & c. $485 \mathrm{G}>\mathrm{T}$ & P.R162L & 3 \\
\hline $\mathrm{C}$ & exon5 & $\mathrm{ZF} 2$ & $3 y$ & c. $485 \mathrm{G}>\mathrm{T}$ & P.R162L & 3 \\
\hline $\mathrm{D}$ & exon5 & $\mathrm{ZF} 2$ & $3 y$ & c. $485 \mathrm{G}>\mathrm{A}$ & P.R162Q & 3 \\
\hline $\mathrm{D}$ & exon5 & $\mathrm{ZF} 2$ & $1 \mathrm{y}$ & c. $485 \mathrm{G}>\mathrm{A}$ & P.R162Q & 3 \\
\hline $\mathrm{D}$ & exon5 & $\mathrm{ZF} 2$ & $12 \mathrm{y}$ & c. $485 \mathrm{G}>\mathrm{A}$ & P.R162Q & 3 \\
\hline $\mathrm{D}$ & exon5 & ZF2 & $6 \mathrm{y}$ & c. $485 \mathrm{G}>\mathrm{A}$ & P.R162Q & 3 \\
\hline $\mathrm{D}$ & exon5 & $\mathrm{ZF} 2$ & $10 \mathrm{y}$ & c. $485 \mathrm{G}>\mathrm{A}$ & P.R162Q & 3 \\
\hline $\mathrm{D}$ & exon5 & $\mathrm{ZF} 2$ & $43 \mathrm{y}$ & c. $485 \mathrm{G}>\mathrm{A}$ & P.R162Q & 3 \\
\hline $\mathrm{D}$ & exon5 & $\mathrm{ZF} 2$ & $3 y$ & c. $485 \mathrm{G}>\mathrm{A}$ & P.R162Q & 3 \\
\hline $\mathrm{E}$ & exon5 & $\mathrm{ZF} 2$ & $30 \mathrm{y}$ & c. $500 \mathrm{~A}>\mathrm{G}$ & P.H167R & 3 \\
\hline $\mathrm{E}$ & exon5 & $\mathrm{ZF} 2$ & $13 \mathrm{y}$ & c. $500 \mathrm{~A}>\mathrm{G}$ & P.H167R & 3 \\
\hline $\mathrm{E}$ & exon5 & $\mathrm{ZF} 2$ & $4 \mathrm{y}$ & c. $500 \mathrm{~A}>\mathrm{G}$ & P.H167R & 3 \\
\hline $\mathrm{F}$ & exon5 & ZF3 & - & c. $551 \mathrm{G}>\mathrm{A}$ & P.R184Q & 3 \\
\hline $\mathrm{F}$ & exon5 & $\mathrm{ZF} 3$ & $9 y$ & c. $551 \mathrm{G}>\mathrm{A}$ & P.R184Q & 3 \\
\hline G & - & - & $3 y$ & c. $1618388 \_589+2308 \mathrm{del}$ & Deletion of ZF1,2,3 & 3 \\
\hline $\mathrm{G}$ & - & - & - & c. $1618388 \_589+2308 \mathrm{del}$ & Deletion of ZF1,2,3 & 3 \\
\hline $\mathrm{H}$ & - & - & $57 \mathrm{y}$ & 7p12.3-p12.1 deletion & Deletion of Ikaros & 3 \\
\hline $\mathrm{H}$ & - & - & $29 \mathrm{y}$ & 7p12.3-p12.1 deletion & Deletion of Ikaros & 3 \\
\hline $\mathrm{H}$ & - & - & $21 \mathrm{y}$ & 7p12.3-p12.1 deletion & Deletion of Ikaros & 3 \\
\hline $\mathrm{H}$ & - & - & $22 \mathrm{y}$ & $7 \mathrm{p} 12.3-\mathrm{p} 12.1$ deletion & Deletion of Ikaros & 3 \\
\hline $\mathrm{H}$ & - & - & $31 \mathrm{y}$ & 7p12.3-p12.1 deletion & Deletion of Ikaros & 3 \\
\hline $\mathrm{H}$ & - & - & $19 \mathrm{y}$ & 7p12.3-p12.1 deletion & Deletion of Ikaros & 3 \\
\hline $\mathrm{H}$ & - & - & - & $7 \mathrm{p} 12.3-\mathrm{p} 12.1$ deletion & Deletion of Ikaros & 3 \\
\hline $\mathrm{H}$ & - & - & - & 7p12.3-p12.1 deletion & Deletion of Ikaros & 3 \\
\hline $\mathrm{H}$ & - & - & - & 7 p12.3-p12.1 deletion & Deletion of Ikaros & 3 \\
\hline $\mathrm{H}$ & - & - & - & 7p12.3-p12.1 deletion & Deletion of Ikaros & 3 \\
\hline $\mathrm{H}$ & - & - & - & 7p12.3-p12.1 deletion & Deletion of Ikaros & 3 \\
\hline $\mathrm{H}$ & - & - & $5 \mathrm{y}$ & 7p12.3-p12.1 deletion & Deletion of Ikaros & 3 \\
\hline $\mathrm{H}$ & - & - & - & $7 \mathrm{p} 12.3$-p12.1 deletion & Deletion of Ikaros & 3 \\
\hline I & exon5 & $\mathrm{ZF} 2$ & $5 \mathrm{y}$ & c. $439 \mathrm{~T}>\mathrm{C}$ & P.C147R & 4 \\
\hline $\mathrm{J}$ & exon5 & $\mathrm{ZF} 2$ & $2 \mathrm{mo}$ & c. $476 \mathrm{~A}>\mathrm{G}$ & P.N159S & 4 \\
\hline K & exon5 & $\mathrm{ZF} 2$ & $10 \mathrm{y}$ & c. $484 \mathrm{C}>\mathrm{T}$ & P.R162W & 4 \\
\hline $\mathrm{K}$ & exon5 & $\mathrm{ZF} 2$ & $12 \mathrm{y}$ & c. $484 \mathrm{C}>\mathrm{T}$ & P.R162W & 4 \\
\hline K & exon5 & $\mathrm{ZF} 2$ & $10 \mathrm{y}$ & c. $484 \mathrm{C}>\mathrm{T}$ & P.R162W & 4 \\
\hline $\mathrm{L}$ & exon5 & $\mathrm{ZF} 2$ & - & c. $485 \mathrm{G}>\mathrm{A}$ & P.R162Q & 4 \\
\hline $\mathrm{L}$ & exon5 & $\mathrm{ZF} 2$ & $20 \mathrm{y}$ & c. $485 \mathrm{G}>\mathrm{A}$ & P.R162Q & 4 \\
\hline $\mathrm{L}$ & exon5 & $\mathrm{ZF} 2$ & $6 y$ & c. $485 \mathrm{G}>\mathrm{A}$ & P.R162Q & 4 \\
\hline M & - & - & - & c. $589+1 \mathrm{G}>\mathrm{A}$ & Deletion of ZF2,3,4 & 4 \\
\hline M & - & - & $3 \mathrm{y}$ & c. $589+1 \mathrm{G}>\mathrm{A}$ & Deletion of ZF2,3,4 & 4 \\
\hline $\mathrm{N}$ & exon6 & $\mathrm{ZF} 4$ & $0 \mathrm{mo}$ & c. $629 \mathrm{~A}>\mathrm{G}$ & P.Y210C & 4 \\
\hline $\mathrm{N}$ & exon6 & $\mathrm{ZF} 4$ & - & c. $629 \mathrm{~A}>\mathrm{G}$ & P.Y210C & 4 \\
\hline $\mathrm{O}$ & exon6 & $\mathrm{ZF} 4$ & $0 \mathrm{mo}$ & c. $629 \mathrm{~A}>\mathrm{G}$ & P.Y210C & 5 \\
\hline
\end{tabular}


After discharge, the patient continued antibiotic therapy and started intravenous immunoglobulin owing to continuous low serum immunoglobulin. Her condition improved.

Most patients with a heterozygous mutation in IKAROS have B-cell deficiency. Mutations are localized within the DNA binding domain (with mutations in exons 4-6). In vitro characterization of the mutated alleles reveals that the mutations are loss-of-function, since they are unable to bind DNA, thus leading to diffused nuclear localization of IKAROS. To our knowledge, including the case we report, there are 15 families affected, making a total of 44 patients worldwide [2-5]. Age at onset ranges from neonate to the sixth decade of life, with a mean age at onset of 13 years. IKZF1-deficient patients are characterized by a phenotype with a prominent decrease in all types of serum immunoglobulin, a lack of peripheral B lymphocyte/NK, and a reversal of the CD4/CD8 ratio. In a cohort of 29 patients, Kuehn et al [3] reported that the clinical manifestations of IKZF1 deficiency were recurrent respiratory infection, autoimmune disease, sepsis, B-cell acute lymphoblastic leukemia, and infection of the central nervous system. More recently, Yoshida et al [2] reported the first case of a patient with severe immunodeficiency that progressed to T-cell acute lymphoblastic leukemia resembling the IKAROSplastic mice model [6]. Furthermore, Hoshino et al [4] and Goldman et al [5] reported a same mutated allele, c.629A $>\mathrm{G}$, leading to Y210C. Both patients had pancytopenia, with onset at a very early age, suggesting a critical role for IKAROS in both human hematopoiesis and immune development. Of note, 2 of the 29 germline-mutated patients in the report by Kuehn et al progressed to B-cell leukemia. It is well recognized that both germline and somatic changes in IKZFI can lead to leukemia, especially B-cell acute lymphoblastic leukemia. Nevertheless, somatic IKZFI deletions are considered to cause more cases of B-cell acute lymphoblastic leukemia than single-nucleotide polymorphisms in IKZF1 do [7]. A selected group of patients presented with mild manifestations and only abnormal antibody levels and decreased B-cell counts. Notably, most asymptomatic individuals harbor the deletion of N-terminal zinc fingers (ZF) instead of point mutations. The asymptomatic state of these individuals might be partially explained by the compensation of the other proteins from the IKAROS family and an absence of the dominant-negative effect. Among the mutated IKZFI genes (Table), p.R162 was frequently mutated, suggesting a "hot spot" mutation. The affected domains are ZF 2-4, with no mutations in ZF 5-6 having been reported.

We report the first Chinese patient with a mutated $I K Z F 1$ gene studied by WES. The mutant gene c.500A $>\mathrm{G}$ has previously been reported in 3 patients [3]. The similarities between these patients include late onset and a tendency to have severe infections (central nervous system infection and sepsis). Although the patient we report has not manifested autoimmune disease to date, her ANA result was positive, thus indicating an autoimmune disease. Interestingly, she had a solid pseudopapillary pancreas tumor, in contrast with the highly common hematological tumor. As Yang et al reported [8], IKAROS was also involved in solid tumors. The immunologic phenotype of the patient we report is consistent with findings in previously reported cases, as well as a significant decrease in B-cell counts and hypogammaglobulinemia. As with other primary antibody immunodeficiency diseases, the treatment of the IKAROS-deficient patients includes mainly immunoglobulin replacement therapy. The condition of the patient we report remains stable on periodic intravenous immunoglobulin.

New techniques have significant benefits for the diagnosis of primary immunodeficiency. Next-generation sequencing of patients previously diagnosed with common variable immunodeficiency has shown different primary immunodeficiency gene defects involving NFKB1, STAT3, CTLA4, PIK3CD, and IKZF1, as well as biallelic mutations in $L R B A$ and $S T X B P 2$. Thus, WES combined with analysis of genes associated with primary immunodeficiency is a costeffective approach for identification of pathogenic mutations in common variable immunodeficiency patients [9]. We recommend WES in female patients with B-cell defects and atypical manifestations.

\section{Funding}

This study was supported by the National Natural Science Foundation of China (No.81373221).

\section{Conflicts of Interest}

The authors declare that they have no conflicts of interest.

\section{References}

1. John LB, Ward AC. The IKAROS gene family: Transcriptional regulators of hematopoiesis and immunity. Mol Immunol. 2011;48(9-10):1272-8.

2. Yoshida N, Sakaguchi H, Muramatsu H, Okuno Y, Song C, Dovat $S$, et al. Germline IKAROS mutation associated with primary immunodeficiency that progressed to T-cell acute lymphoblastic leukemia. Leukemia. 2017;31(5):1221-3.

3. Kuehn HS, Boisson B, Cunningham-Rundles C, Reichenbach J, Stray-Pedersen A, Gelfand EW, et al. Loss of B Cells in Patients with Heterozygous Mutations in IKAROS. N Engl J Med. 2016;374:1032-43.

4. Hoshino A, Okada S, Yoshida K, Nishida N, Okuno Y, Ueno $\mathrm{H}$, et al. Abnormal hematopoiesis and autoimmunity in human subjects with germline IKZF1 mutations. J Allergy Clin Immunol. 2017;140(1):223-31.

5. Goldman FD, Gurel Z, Al-Zubeidi D, Fried AJ, Icardi M, Song C, et al. Congenital pancytopenia and absence of $B$ lymphocytes in a neonate with a mutation in the IKAROS gene. Pediatr Blood Cancer. 2011;58:591-7.

6. Dumortier A, Jeannet R, Kirstetter P, Kleinmann E, Sellars M, dos Santos NR et al. Notch activation is an early and critical event during T-Cell leukemogenesis in IKAROS-deficient mice. Mol Cell Biol. 2006;26:209-20.

7. Olsson L, Johansson B. IKAROS and leukaemia. Br J Haematol. 2015;169(4):479-91.

8. Yang LM, Luo YM, Wei JF. Integrative genomic analyses on IKAROS and its expression related to solid cancer prognosis. Oncol Rep. 2010;24(2):1-7. 
9. Maffucci P, Filion CA, Boisson B, Itan $Y$, Shang L, Casanova $\mathrm{J}-\mathrm{L}$, et al. Genetic Diagnosis Using Whole Exome Sequencing in Common Variable Immunodeficiency. Front Immunol. 2016;7:696-9.

1 Manuscript received July 26, 2017; accepted for publication October 9, 2017.

\section{Xiao-chuan Wang}

The Children's Hospital of Fudan University No. 399 Wanyuan Road, Shanghai, Minhang District E-mail: xchwang@shmu.edu.cn 